\title{
Evaluation of Physio-morphological Traits in Upland Rice under Water Limited Environment
}

\author{
Mudit Srivastava* and A.K. Singh \\ Narendra Deva University of Agriculture and Technology, Kumarganj, \\ Faizabad-224 229 (U.P.), India \\ *Corresponding author
}

Keywords

Drought, Irrigated, Upland rice, GCV, PCV, Genetic advance and heritability

Article Info

Accepted:

28 February 2018

Available Online:

10 March 2018

A B S T R A C T

An attempt was made to evaluate eighteen physio-morphological traits and grain yield in eighteen genotypes of upland rice under irrigated and flowering stage drought condition. High estimates of phenotypic (PCV) and genotypic (GCV) coefficient of variation were observed for sterile grains per panicle, grain yield apparent contribution rate, water potential, straw yield and total biomass at maturity in drought stress condition. Fourteen out of nineteen characters under study showed higher PCV and GCV values in drought condition as compared to corresponding estimates in irrigated condition which indicated that water stress was responsible for expressing greatest degree of variability in case of most of the physio-morphological traits in the same material. High estimates of heritability in broad sense coupled with high genetic advance in per cent of mean were recorded for water potential, fertile grains per panicle, sterile grains per panicle, straw yield, total biomass at flower total biomass at maturity, ACR, root length, root volume and grain yield in both conditions and panicle length, ATR, membrane thermo stability and root dry weight in drought conditions only. The physico-morphological traits exhibiting high heritability and genetic advance would provide high response to selection practiced for their improvement.

\section{Introduction}

Over half of the world's rice in grown under rainfed conditions where drought occurs. Drought stress is a major constraint to rice (Oryza sativa L.) production and yield stability in many rainfed regions of Asia,
Africa and South America. In Asia nearly $40 \%$ of the rainfed rice grown under rainfed upland conditions. Under water stress condition, the most effective defense mechanism available to the rice plant is a good root system, consisting of deep and mostly thick roots which enable the plant to 
avoid the adverse effects of internal water deficit (Chang et al., 1972). Plant selections with desirable root characteristic have been major objective in breeding drought resistant variety of rice (Chang and Vergara, 1975).

Selection has to be practiced for improving the agronomically important plant traits at one or more stages of a successful breeding programme aimed at development of superior varieties for normal or stress environment. Selection act on existing genetic variability to bring improvement in plant characters. The effectiveness of selection in improving important traits a well as economic yield depends largely upon the nature and magnitude of genetic variability existing in the germplasm or breeding materials for traits which contribute towards expression of yield in a specific stress or non-stress environment. Since the expression of genetic variation in same material for quantitative characters usually exhibits substantial differences with changing environments, the assessment of genetic variability in particular environments is essential for determining the appropriate selection strategy and breeding methodology to be followed for evolving superior varieties for target environment. Selection for improved yield in rice under drought has been hampered by the unpredictatability of drought events, which means that selection pressure is generally inconsistent and possibly contradictory, across the years. The problems encountered due to highly unpredictable and variable occurrence of drought are compounded further by the extremely complex and intriguing nature of physiological mechanism responsible for conditioning the drought tolerance in rice.

\section{Materials and Methods}

The experimental material for the present study comprising eighteen genotypes of rice exhibited wide spectrum of variation in respect of genetic background, drought tolerance, yield potential and physiomorphological traits. The material consisted of improved varieties/cultivars (Monoberekan, TN-1, Azucena, Vandana, NDR 359, IR 64, Saita), double haploid lines (DGI-21, DGI-75, DGI-138, DGI-152, DGI379, DSU-18-6) and introgression lines (P0088, P-0090, P-0326 and P-0397). The eighteen lines were evaluated in irrigated control and heading stage managed stress drought conditions during successive wet seasons for 2004-05 and 2005-06. Each of the four experiments were conducted in randomized block design with three replications using $2.0 \times 4.0 \mathrm{~m}^{2}$ plots with intra- and inter-row spacing of $15 \mathrm{~cm}$ and 20 $\mathrm{cm}$, respectively. The managed drought at heading stage was created by withholding water for 15 days upto $80 \mathrm{~K} \mathrm{~Pa}$ at $0-15 \mathrm{~cm}$ soil profile and $60 \mathrm{~K} \mathrm{~Pa}$ at $30 \mathrm{~cm}$ soil depth.

The phenotypic (PCV) and genotypic (GCV) coefficients of variation and heritability in broad sense $\left(h^{2} b\right)$ were computed according to Burton and de Vane (1953), while genetic advance in per cent of mean $(\overline{\mathrm{Ga}})$ was worked out following Johnson et al. (1995).

\section{Results and Discussion}

The general mean and range for nineteen physio-morphological traits in irrigated and drought conditions are presented in Table 1. Water potential, sterile grains per panicle ACR and membrane thermo-stability exhibited markedly higher general mean and range in drought condition than irrigated condition. Panicle length, straw yield, harvest-index, total biomass at maturity, ATR, root volume and grain yield showed lower mean with higher range in drought stress than irrigated control which indicated that drought stress caused reduction in mean performance while increasing the differences in relative performance of genotypes for these traits. 
Table.1 Estimates of range, grand mean for nineteen characters rice germplasm under irrigated and drought conditions

\begin{tabular}{|l|c|c|c|c|}
\hline \multirow{2}{*}{ Characters } & \multicolumn{2}{|c|}{ General mean } & \multicolumn{2}{c|}{ Range } \\
\hline Plant height & Irrigated & Drought & Irrigated & Drought \\
\hline Water potential & 88.19 & 78.47 & $70-110$ & $\mathbf{6 4 - 9 7}$ \\
\hline RWC\% & 192.57 & 280.04 & $142-263$ & $\mathbf{1 8 2 - 4 4 0}$ \\
\hline Panicle length & 83.18 & 63.38 & $73-97$ & $\mathbf{5 3 - 6 7}$ \\
\hline Fertile grains & 23.85 & 20.26 & $18-27$ & $\mathbf{1 5 - 2 6}$ \\
\hline Sterile grains & 76.46 & 54.78 & $37-120$ & $\mathbf{3 4 - 9 2}$ \\
\hline Ear bearing tiller (EBT) & 24.19 & 30.07 & $11-43$ & $\mathbf{1 6 - 5 0}$ \\
\hline Straw yield & 13.26 & 9.95 & $10-1$ & $\mathbf{8 - 1 2}$ \\
\hline Harvest index (\%) & 800.25 & 592.8 & $630-925$ & $\mathbf{3 7 1 - 8 5 3}$ \\
\hline Test weight (g) & 43.50 & 34.18 & $40-51$ & $\mathbf{2 9 - 4 2}$ \\
\hline Total biomass at flowering & 21.21 & 18.13 & $17-24$ & $\mathbf{1 3 - 2 0}$ \\
\hline Total biomass at maturity & 34.38 & 26.03 & $26-44$ & $\mathbf{1 9 - 3 4}$ \\
\hline Apparent Translocation Rate & 43.87 & 32.10 & $32-64$ & $\mathbf{1 9 - 5 3}$ \\
\hline (ATR) & 0.676 & 0.468 & $050-0.86$ & \\
\hline Apparent Contribution Rate & & & & $\mathbf{6 3 - 1 4 6}$ \\
\hline (ACR) & 64.45 & 86.24 & $46-83$ & $\mathbf{3 7 - 7 0}$ \\
\hline Membrane thermostability & 39.11 & 51.75 & $35-42$ & $\mathbf{2 6 - 8 5}$ \\
\hline Root length & 57.90 & 41.76 & $33-96$ & $\mathbf{2 2 - 1 2 7}$ \\
\hline Root volume & 59.43 & 53.03 & $36-115$ & $\mathbf{4 - 1 6}$ \\
\hline Root dry weight & 9.20 & 8.70 & $5-17$ & $\mathbf{2 2 8 - 5 3 9}$ \\
\hline Grain yield & $\mathbf{5 2 0 . 7 0}$ & $\mathbf{3 7 1 . 5 7}$ & $390-664$ & \\
\hline
\end{tabular}


Table.2 Phenotypic (PCV) ad genotypic (GCV) coefficients of variation, heritability in broad sense $\left(\mathrm{h}^{2}\right)$ and genetic advance in per cent of mean (GA)

\begin{tabular}{|c|c|c|c|c|c|c|c|c|}
\hline \multirow[t]{2}{*}{ Characters } & \multicolumn{2}{|c|}{ GCV } & \multicolumn{2}{|c|}{ PCV } & \multicolumn{2}{|c|}{$h^{2}(b)$} & \multicolumn{2}{|c|}{ GA in \% of mean } \\
\hline & $\mathbf{N}$ & D & $\mathbf{N}$ & D & $\mathbf{N}$ & D & $\mathbf{N}$ & D \\
\hline Plant height & 12.71 & 11.41 & 15.14 & 14.08 & 70.50 & 65.60 & 21.97 & 19.03 \\
\hline Water potential & 14.55 & 23.83 & 14.60 & 23.85 & 99.30 & 99.80 & 29.86 & 49.04 \\
\hline RWC\% & 8.32 & 4.86 & 8.33 & 4.87 & 100.00 & 99.60 & 17.14 & 10.00 \\
\hline Panicle length & 8.04 & 12.18 & 8.09 & 12.23 & 98.70 & 99.10 & 16.43 & 24.97 \\
\hline Fertile grains & 26.95 & 29.99 & 28.72 & 30.96 & 88.00 & 93.80 & 52.07 & 59.83 \\
\hline Sterile grains & 35.95 & 26.96 & 37.03 & 27.75 & 94.30 & 94.40 & 71.91 & 62.94 \\
\hline Ear bearing tiller (EBT) & 11.80 & 8.35 & 16.35 & 15.18 & 52.10 & 30.30 & 17.57 & 9.44 \\
\hline Straw yield & 11.01 & 23.73 & 11.08 & 23.74 & 98.80 & 100.00 & 22.55 & 48.37 \\
\hline Harvest index (\%) & 5.14 & 8.91 & 6.38 & 10.21 & 64.80 & 66.90 & 8.52 & 14.07 \\
\hline Test weight (g) & 6.46 & 15.48 & 11.55 & 11.99 & 31.30 & 55.30 & 7.44 & 13.62 \\
\hline Total biomass at flowering & 14.38 & 23.51 & 15.90 & 17.06 & 81.80 & 82.30 & 26.78 & 28.92 \\
\hline Total biomass at maturity & 19.96 & 27.69 & 20.81 & 24.33 & 92.00 & 93.30 & 28.06 & 46.78 \\
\hline $\begin{array}{ll}\text { Apparent } & \text { Translocation } \\
\text { Rate (ATR) } & \\
\end{array}$ & 9.97 & 25.12 & 10.44 & 29.46 & 91.20 & 88.30 & 19.23 & 53.41 \\
\hline $\begin{array}{ll}\text { Apparent } & \text { Contribution } \\
\text { Rate (ACR) } & \\
\end{array}$ & 18.82 & 18.30 & 18.82 & 25.13 & 99.90 & 99.90 & 38.74 & 51.73 \\
\hline Membrane thermostability & 4.42 & 34.48 & 7.08 & 18.73 & 38.90 & 94.90 & 5.67 & 36.71 \\
\hline Root length & 30.49 & 47.99 & 30.67 & 4.488 & 98.80 & 100.00 & 60.84 & 71.00 \\
\hline Root volume & 35.60 & 37.21 & 35.92 & 47.99 & 98.30 & 100.00 & 72.71 & 98.83 \\
\hline Root dry weight & 35.83 & 37.21 & 35.87 & 37.27 & 99.80 & 99.70 & 77.36 & 76.33 \\
\hline Grain yield & 16.69 & - & 16.70 & 25.36 & 99.90 & 99.90 & 34.36 & 52.19 \\
\hline
\end{tabular}


From Table 2 it was showed that the high estimates (> 20\%) of phenotypic (PCV) and genotypic $(\mathrm{GCV})$ coefficients of variation were observed for root dry weight, root volume, sterile grains per panicle in both conditions.

High estimates of heritability and genetic advance were recorded for water potential, fertile grains per panicle, sterile grains per panicle, straw yield, total biomass at flowering, total biomass at maturity, ACR, root length, root volume, root dry weight and grain yield emerged as the characters which may provide high response to selection in irrigated as well as drought conditions. In addition, panicle length, ATR and membrane thermostability appeared as highly desirable traits for improvement through selection under drought stress only. High values of $h^{2}$ and $\overline{\text { Ga }}$ for grains per panicle was also recorded by Bhattacharya and Mishra (1981), Maurya et al. (1986), Singh (1992), Sharma and Roy (1993) and Kumar et al. (1994). High values of $h^{2}$ and genetic advance for harvest-index, grain yield and spikelet fertility were also recorded by Singh (1992) and Kumar et al., (1994).

Among these considerable increase in mean performance and range recorded for water potential, sterile grains per panicle, ACR and membrane thermostability in drought condition suggested that these traits merit special attention because these would be highly useful indiscriminating rice genotypes under drought stress.

\section{References}

Bhattacharya, R.K. and Mishra, B. (1981). Genetic variability for quantitative characters in rice grown on sodic and non-sodic soil. Indian J. Agric. Sci., 51 : 546-549.

Burtorn, G.W. and De Vane, E.H. (1953). Estimating heritability in tall fescue (Festuca arundinacea) from replication clonal material. Agron. J., 478-481.
Chang (1972) and Ghildyal and Tomar (1982). Also found deep root system in drought resistant varieties. Euphytica, $100: 77-89$.

Chang, T.T. and Vergera, B.S. (1975). Varietal diversity and morpho-agronomic characteristics of upland rice. In: Major Research on Upland rice. Int. Rice. Res. Inst., Los Banos, Philippines, pp. 72-90.

Gurudachalam, S. (1972). Studies on coheritability correlations, selection index and path co-efficient analysis in rice an unpublished M.Sc. (Ag.) Thesis, B.H.U.

Johnson, H.W.H., Robinson, H.F. and Comstock, R.E. (1955). Estimates of genetic and environmental variability in Soybean. Agron. J., 47: 314-318.

Kumar, R., Krishnapal, Mandal, S.K., Ramsankar, R., Prasad, S.C. and Rai, R. (1994). Genetic study of major characters in upland rice. Environmental and Ecology, 12: 263-265.

Maurya, D.M., Singh, S.K. and Singh, R.S. (1986). Genetic variability in lowland rice cultivars of U.P., India. Inter. Rice Res. News letter, 11 (4) : 13-14.

Panse, V.G. and Sukhatme, P.V. (1967). Statistical methods for agricultural workers. ICAR, New Delhi.

Rai, N.R., Devika, R., Regind, A. and Joseph, C.A. (1992). Correlation of yield and yield components in medium duration rice cultivars. Environment and Ecology, 10: 469470.

Searle, S.R. (1961). Phenotypic, genotypic and environmental correlations, Biometrics, 17: 474-480.

Sharma, R.N. and Roy, A. (1993). Studies on variability and inter relationship of field attributes in Jhum rice. Annals of Agril. Res., 14: 311-316.

Singh, D. and Sahay, R.K. (1992). Drought stress in cotton identification of critical growth stages. Plant Physiol. Biochem., 19 (1): 5557.

\section{How to cite this article:}

Mudit Srivastava and Singh, A.K. 2018. Evaluation of Physio-morphological Traits in Upland Rice under Water Limited Environment. Int.J.Curr.Microbiol.App.Sci. 7(03): 3691-3695.

doi: https://doi.org/10.20546/ijcmas.2018.703.427 